\title{
Sirtuin 6 regulates the proliferation and survival of clear cell renal cell carcinoma cells via B-cell lymphoma 2
}

\author{
JUN AN $^{1}$, JIEPING YANG $^{1}$, YANG YAO $^{2}$, KAINING LU $^{3}$, ZHIQIANG ZHAO $^{4}$, MENG YU $^{5}$ and YUYAN ZHU ${ }^{1}$ \\ ${ }^{1}$ Department of Urology, The First Hospital of China Medical University, Shenyang, Liaoning 110001; \\ ${ }^{2}$ Department of Physiology, Shenyang Medical College, Shenyang, Liaoning 110034; \\ ${ }^{3}$ Department of Urology and Nephrology, Ningbo First Hospital, The Affiliated Hospital of Zhejiang University, \\ Ningbo, Zhejiang 315010; ${ }^{4}$ Department of Intensive Care Unit, Mudanjiang Forestry Center Hospital, Mudanjiang, \\ Heilongjiang 157000; ${ }^{5}$ Key Laboratory of Transgenic Animal Research, Department of Laboratory Animal Science, \\ China Medical University, Shenyang, Liaoning 110122, P.R. China
}

Received March 30, 2020; Accepted December 14, 2020

DOI: $10.3892 / 01.2021 .12554$

\begin{abstract}
Sirtuin 6 (SIRT6) is a member of the third family of longevity proteins (SIRTs) that is involved in the development of different types of cancer. However, the potential role of SIRT6 in clear cell renal cell carcinoma (ccRCC) and its molecular mechanism have not yet been fully elucidated. Therefore, the present study aimed to investigate the association between SIRT6 and ccRCC, and to further examine the underlying mechanism of its effect on ccRCC proliferation, using bioinformatics analysis, and in vitro and in vivo experiments. The results of the present study demonstrated that SIRT6 was upregulated in ccRCC tissues. In addition, bioinformatics analysis revealed that high SIRT6 expression was closely associated with poor prognosis of patients with ccRCC. In vitro experiments demonstrated that silencing SIRT6 expression in ccRCC-derived 769-P and 786-O cells significantly inhibited their proliferation, migration and invasion. Consistent with these results, in vivo assays demonstrated that SIRT6 knockdown markedly attenuated tumor growth arising from 769-P cells. Furthermore, depletion of SIRT6 enhanced the sensitivity of ccRCC cells to cisplatin. Notably, silencing SIRT6 expression decreased B-cell lymphoma 2 (Bcl-2) expression and increased Bax expression, respectively. Taken together, these results suggest
\end{abstract}

Correspondence to: Professor Yuyan Zhu, Department of Urology, The First Hospital of China Medical University, 155 Nanjing North Street, Shenyang, Liaoning 110001, P.R. China

E-mail:yyzhu@cmu.edu.cn

Mrs. Meng Yu, Key Laboratory of Transgenic Animal Research, Department of Laboratory Animal Science, China Medical University, $77 \mathrm{Pu}$-he Road, Shenyang North New Area, Shenyang, Liaoning 110122, P.R. China

E-mail: yumeng@cmu.edu.cn

Key words: sirtuin 6, B-cell lymphoma 2, clear cell renal cell carcinoma, proliferation, metastasis that SIRT6 acts as a proto-oncogene in ccRCC through the augmentation of the Bcl-2-dependent pro-survival pathway, and may be used as a therapeutic target for patients with ccRCC.

\section{Introduction}

Renal cell carcinoma (RCC) accounts for $>90 \%$ of renal cancers (1). Among the RCC subtypes, renal clear cell carcinoma (ccRCC) accounts for $\sim 80 \%$ of all cases (2). The effects of radiotherapy and chemotherapy on $\mathrm{RCC}$ remain unsatisfactory (3), and despite following nephrectomy, the risk of recurrence or metastasis is up to $40 \%(4,5)$. Thus, it remains essential to identify novel therapeutic targets and potential prognostic biomarkers.

SIRT6 is a member of the silent information regulatory protein family, and is a histone deacetylase and ADP-ribosyltransferase protease that depends on nicotinamide adenine dinucleotide (6). SIRT6 plays an important role in several biological processes, including transcriptional regulation, glucose/lipid metabolism, DNA damage repair and life span regulation $(6,7)$. Increasing evidence suggests that SIRT6 expression is closely associated with the occurrence and development of different types of cancer $(8,9)$. For example, SIRT6 plays a key regulatory role in liver cancer (10), lung cancer (11), breast cancer (12), colorectal cancer (13) and reproductive system cancer $(14,15)$.

It has also been suggested that SIRT6 may play a dual role in cancers (16). For example, in non-small cell lung cancer (NSCLC), SIRT6 suppresses Twist1 expression and thereby inhibits the proliferation of NSCLC cells (11). Conversely, SIRT6 interacts with $\mathrm{Ku} 70$ in liver cancer, which promotes its deacetylation to block Bax expression and thereby potentiates its mitochondrial translocation to inhibit apoptotic cell death of liver cancer cells (17). Currently, the potential role of SIRT6 and its underlying molecular mechanisms in renal cancer remain unknown. Therefore, in the present study, the expression pattern, clinical significance and biological function of SIRT6 in ccRCC was investigated. 


\section{Materials and methods}

Human samples. A total of 60 pairs of ccRCC tissues and adjacent normal tissues ( $\geq 2 \mathrm{~cm}$ away from the edge of the tumor site) used in the present study were obtained from patients who were pathologically diagnosed with ccRCC and who had partial (47 cases) or radical nephrectomy (13 cases) between May 2018 and November 2019 at the First Hospital of China Medical University (Shenyang, China). The average age of the patients was 67.6 years (age range, 28-80 years) and there were 37 males and 23 females. Tissue samples were stored at $-80^{\circ} \mathrm{C}$ until subsequent experimentation.

The proteins extracted from 20 pairs of tissue samples were assessed via western blot analysis to detect SIRT6 protein expression in ccRCC tissues and adjacent normal tissues. According to the renal cancer stage defined in the eighth edition of American Joint Committee on Cancer (18), the remaining 40 patients with ccRCC were divided into two groups, TNM ( $\mathrm{n}=28$; I-II) or TNM ( $\mathrm{n}=12$; III-IV). The RNAs extracted from 40 pairs of tissue samples were assessed via reverse transcription-quantitative (RT-q)PCR analysis, and the association between SIRT6 expression and the clinicopathological characteristics of patients with ccRCC was assessed using the $\chi^{2}$ test. The present study was approved by the Ethics Committee of the First Hospital of China Medical University (Institutional review board no. 2018-64-2; Shenyang, China), and performed in accordance with the Declaration of Helsinki (19). Written informed consent was provided by all patients prior to the study start.

Cell culture. ccRCC-derived 769-P and 786-O cells were purchased from Shanghai Institute for Biological Sciences, Chinese Academy of Sciences. Cells were maintained in RPMI-1640 medium supplemented with 10\% heat-inactivated fetal bovine serum (FBS, both purchased from Gibco; Thermo Fisher Scientific, Inc.), 100 units $/ \mathrm{ml}$ penicillin and $100 \mu \mathrm{g} / \mathrm{ml}$ streptomycin (Thermo Fisher Scientific, Inc.), at $37^{\circ} \mathrm{C}$ with $5 \% \mathrm{CO}_{2}$.

Cell transfection. Small interfering (si)RNA targeting two different sites of SIRT6(siRNA-SIRT6\#1 and siRNA-SIRT6\#2) and its negative control (siRNA-NC) were purchased from Shanghai GenePharma Co., Ltd. siRNA was transfected into the cells at a final concentration of $40 \mathrm{pM}$, according to the manufacturer's instructions. ccRCC cells were transfected using Lipofectamine ${ }^{\circledR}$ RNAiMAX (Invitrogen; Thermo Fisher Scientific, Inc.) and opti-MEM (Gibco; Thermo Fisher Scientific, Inc.). After transfection, the cells were incubated at $37^{\circ} \mathrm{C}$ for $48 \mathrm{~h}$ for subsequent cell experiments. The sequences of the siRNAs are listed in Table I.

B-cell lymphoma 2 (Bcl-2) overexpression vectors (pcDNA3.0-Bcl-2) and empty vectors (pcDNA3.0) were purchased from Obio Technology Co., Ltd., and ccRCC cells were transfected using Lipofectamine ${ }^{\circledR} 3000$ (Invitrogen; Thermo Fisher Scientific, Inc.) and opti-MEM (Gibco; Thermo Fisher Scientific, Inc.). Transfection efficiency was verified by western blot analysis.

In the rescue experiment, the 769-P cells were transfected with si-SIRT6\#1 and incubated at $37^{\circ} \mathrm{C}$ with $5 \% \mathrm{CO}_{2}$ for $24 \mathrm{~h}$, then transfected with $\mathrm{Bcl}-2$ overexpression vectors and incubated under the same conditions. Transfection efficiency was verified using western blot analysis $24 \mathrm{~h}$ later, then the Cell Counting Kit-8 experiment was performed.

Lentiviral short hairpin (sh)RNA vector construction and infection. To construct the ccRCC cells with stable SIRT6 knockdown in in vivo animal studies, a lentiviral shRNA vector targeting the human SIRT6 gene (pLenti-CMV-shSIRT6-PGK-Puro) was constructed by Obio Technology Co., Ltd. The sequences used to construct the targeting sh-SIRT6 and sh-NC are listed in Table I.

293 T cells were purchased from the Cell Bank of Type Culture Collection of Chinese Academy of Sciences and maintained in DMEM (Gibco; Thermo Fisher Scientific, Inc.) supplemented with $10 \% \mathrm{FBS}$, at $37^{\circ} \mathrm{C}$ with $5 \% \mathrm{CO}_{2}$. Following incubation for $24 \mathrm{~h}$ at $37^{\circ} \mathrm{C}$, the cells were transfected with $0.5 \mu \mathrm{g}$ sh-SIRT6 or sh-NC using FuGENE ${ }^{\mathrm{TM}}$ HD transfection reagent (Promega Corporation) and the Packaging Plasmid Mix (Sigma-Aldrich; Merck KGaA). Following incubation overnight at $37^{\circ} \mathrm{C}$, the media were replaced with $10 \mathrm{ml}$ fresh medium and the virus-containing supernatants (sh-NC and sh-SIRT6) were collected after $48 \mathrm{~h}$.

769-P cells were transfected with sh-NC and sh-SIRT6, respectively, at $37^{\circ} \mathrm{C}$ for $72 \mathrm{~h}$. To establish stable cell lines, $2 \mu \mathrm{g} / \mathrm{ml}$ puromycin (cat. no. A1113803; Thermo Fisher Scientific, Inc.) was added to the medium for 1 week following transfection with the lentiviral vectors. Knockdown efficiency was verified via RT-qPCR and western blot analyses. $R T-q P C R$. Total RNA was extracted from tissues using TRIzol ${ }^{\circledR}$ reagent (Thermo Fisher Scientific, Inc.), according to the manufacturer's protocol. The concentration and purity of the RNA solution were detected using a NanoDrop 2000 spectrophotometer (NanoDrop Technologies; Thermo Fisher Scientific, Inc.). Total RNA was reverse transcribed into cDNA using the PrimeScript ${ }^{\mathrm{TM}}$ RT Master Mix (cat. no. RR036A; Takara Biotechnology Co., Ltd.), at $37^{\circ} \mathrm{C}$ for $15 \mathrm{~min}$ and $85^{\circ} \mathrm{C}$ for $5 \mathrm{sec}$, and was held at $4^{\circ} \mathrm{C}$ until further use. qPCR was subsequently performed using the SYBR premix ExTaq ${ }^{\mathrm{TM}}$ kit (cat. no. RR420A; Takara Biotechnology Co., Ltd.). Relative expression levels were detected using a LightCycler ${ }^{\mathrm{TM}} 480$ II system (Roche Diagnostics) and normalized to the internal reference gene $\beta$-actin. The relative expression levels were calculated using the $2^{-\Delta \Delta \mathrm{Cq}}$ method (20). The following thermocycling conditions were used: Initial denaturation at $95^{\circ} \mathrm{C}$ for $5 \mathrm{~min}, 95^{\circ} \mathrm{C}$ for $10 \mathrm{sec}$ and $60^{\circ} \mathrm{C}$ for $30 \mathrm{sec}$ for 45 cycles, with a final cycle of $95^{\circ} \mathrm{C}$ for $15 \mathrm{sec}, 60^{\circ} \mathrm{C}$ for $1 \mathrm{~min}$ and $40^{\circ} \mathrm{C}$ for $30 \mathrm{sec}$. The primer sequences used for qPCR are listed in Table I.

For the expression of SIRT6 in patients with ccRCC in different clinical stages, $\beta$-actin was used as internal controls for expression data normalization. The expression of tumor tissue was determined using the $2^{-\Delta \Delta C q}$ method by comparing with the adjacent normal tissue.

Western blot analysis. Total protein was extracted from the 769-P and 786-O cells using RIPA lysis buffer (Sigma-Aldrich; Merck KGaA). Protein concentration was determined using the BCA method (Beijing Solarbio Science \& Technology Co.,Ltd.) and $40 \mu \mathrm{g}$ protein/lane was separated by $10 \%$ SDS-PAGE. The 
Table I. Sequences of siRNAs and shRNAs, and the primers used for quantitative PCR.

A, siRNA names and sequences

\begin{tabular}{ll}
\hline siRNA & Sequence (5'-3') \\
si-NC forward & UUCUCCGAACGUGUCACGUTT \\
si-NC reverse & ACGUGACACGUUCGGAGAATT \\
si-SIRT6\#1 forward & GUGGAAGAAUGUGCCAAGUTT \\
si-SIRT6\#1 reverse & ACUUGGCACAUUCUUCCACTT \\
si-SIRT6\#2 forward & GAAGAAUGUGCCAAGUGUATT \\
si-SIRT6\#2 reverse & UACACUUGGCACAUUCUUCTT
\end{tabular}

$\mathrm{B}$, shRNA names and sequences

\begin{tabular}{ll}
\hline shRNA & Sequence $\left(5^{\prime}-3^{\prime}\right)$ \\
sh-NC & TTCTCCGAACGTGTCACGT \\
sh-SIRT6 & GAAGAATGTGCCAAGTGTA
\end{tabular}

C, Primer names and sequences

\begin{tabular}{ll} 
Primer & Sequence $\left(5^{\prime}-3^{\prime}\right)$ \\
SIRT6 forward & CCATCCTAGACTGGGAGGACT \\
SIRT6 reverse & GGATCTGCAGCGATGTACCC \\
$\beta$-actin forward & CATGCCATCCTGCGTCTGGAC \\
$\beta$-actin reverse & CAGGCAGCTCGTAGCTCTTCTCC \\
\hline
\end{tabular}

si, small interfering; NC, negative control; SIRT6, sirtuin 6; sh, short hairpin.

separated proteins were subsequently transferred onto PVDF membranes (EMD Millipore) and blocked with 5\% skimmed milk at room temperature for $30 \mathrm{~min}$. Subsequently, appropriate primary antibody dilutions were prepared and incubated with the membranes overnight at $4^{\circ} \mathrm{C}$. The antibodies included rabbit anti-SIRT6 (cat. no. 2590s; Cell Signaling Technology, Inc.), rabbit anti-Bcl-2 (cat. no. ab182858; Abcam), rabbit anti-Bax (cat. no. ab32503; Abcam) and rabbit anti- $\beta$-actin (cat. no. BS0061; BIOSS) (all 1:1,000). After washing with PBS three times, the membranes were incubated with HRP-conjugated goat anti-rabbit IgG (1:5,000; cat. no. sc2357; Santa Cruz Biotechnology, Inc.) for $1 \mathrm{~h}$ at room temperature. And protein bands were visualized using the Pierce ${ }^{\mathrm{TM}}$ ECL Plus western blotting substrate (Thermo Fisher Scientific, Inc.). To determine the expression intensity of SIRT6 relative to normal adjacent tissues more accurately, the relative expression levels were detected using ImageJ v1.51 software (National Institutes of Health) and normalized to the internal reference gene $\beta$-actin. Subsequently, the ratio of the tumor tissue compared to the adjacent normal tissue was calculated as the relative expression level.

CCK- 8 assay. The effect of SIRT6 on cell proliferation was assessed via the CCK- 8 assay. Cells were collected $24 \mathrm{~h}$ post-transfection and seeded into a 96 -well plate at a density of 1,500 cells/well. Following incubation for $4 \mathrm{~h}$ at $37^{\circ} \mathrm{C}$, with $5 \% \mathrm{CO}_{2}, 10 \mu \mathrm{l} \mathrm{CCK}-8$ reagent (Vazyme Biotech Co., Ltd.) was added to each well and the reaction mixtures were incubated for an additional $3 \mathrm{~h}$ at $37^{\circ} \mathrm{C}$, with $5 \% \mathrm{CO}_{2}$. Cell proliferation was subsequently analyzed at a wavelength of $450 \mathrm{~nm}$, using a microplate reader (Bio-Rad Laboratories, Inc.).

Colony formation assay. The effect of SIRT6 on cell proliferation and the association between SIRT6 and cisplatin sensitivity of ccRCC were assessed using the colony formation assay. Cells were collected $24 \mathrm{~h}$ post-transfection and seeded into 6-well plates at a density of 1,500 cells/well. Following incubation for 10 days at $37^{\circ} \mathrm{C}$ with $5 \% \mathrm{CO}_{2}$, cells were fixed with $4 \%$ paraformaldehyde solution for $30 \mathrm{~min}$ at room temperature, washed three times with PBS and subsequently stained with $0.1 \%$ crystal violet (Sigma-Aldrich; Merck KGaA) for $30 \mathrm{~min}$ at room temperature. Cells were extensively re-washed with PBS and images were captured using a light microscope (magnification, $x 40$ ). The number of viable colonies was defined as $>50$ cells/colony. The results were quantified using ImageJ v1.51 software (National Institutes of Health).

For the cisplatin sensitivity assay, the 769-P cells were collected $24 \mathrm{~h}$ post-transfection and seeded into 6-well plates at a density of 2,000 cells/well, then incubated with DMSO or $2.5 \mu \mathrm{M}$ cisplatin at $37^{\circ} \mathrm{C}$ with $5 \% \mathrm{CO}_{2}$ for 2 weeks. Subsequently, the cells were fixed, stained and counted according to the aforementioned method.

Transwell assay. The Transwell assay was performed to assess the effect of SIRT6 on the migratory and invasive abilities of ccRCC cells. Cells were collected $24 \mathrm{~h}$ post-transfection. Briefly, $1 \times 10^{5}$ cells were plated in the upper chambers of Transwell plates (Corning, Inc.) in $200 \mu 1$ serum-free RPMI-1640 medium (Gibco; Thermo Fisher Scientific, Inc.). For the invasion assay, Transwell membranes were precoated with $55 \mu$ l Matrigel (1:7 dilution, Corning, Inc.) for $30 \mathrm{~min}$ at $37^{\circ} \mathrm{C}$, RPMI-1640 medium $(600 \mu \mathrm{l})$ supplemented with $10 \%$ FBS was plated in the lower chambers. Following incubation for $24 \mathrm{~h}$ at $37^{\circ} \mathrm{C}$ and $5 \% \mathrm{CO}_{2}$, the cells were fixed with $4 \%$ formaldehyde at room temperature for $30 \mathrm{~min}$ and subsequently stained with $0.1 \%$ crystal violet at room temperature for $30 \mathrm{~min}$. Cell were washed three times with PBS and the unmigrated cells were removed using cotton swabs. Images were captured using a Leica DM3000 microscope (Leica Microsystems $\mathrm{GmbH}$; magnification, $\mathrm{x} 40$ and $\mathrm{x} 100)$. The numbers of cells were counted in $\geq 5$ independent fields of view, using ImageJ v1.51 software (National Institutes of Health).

In vivo animal studies. A total of 42 male BALB/c nude mice (body weight, 18-20 g; aged 4-6 weeks) were purchased from Beijing Vital River Laboratory Animal Technology Co., Ltd. Of these, 30 mice were used for pre-experiments to determine the ccRCC cell lines (769-P or 786-O), whether to use Matrigel and different inoculated cell numbers. The remaining 12 mice were used for the in vivo tumor formation experiment. All animal experiments were approved by the Ethics Committee of Medical Experimental Animal Welfare of China Medical University (approval no. 2019227; Shenyang, China), and performed at the Experimental Animal Department of China Medical University. 
The experimental mice were classified into two groups (n=6 mice/group), sh-SIRT6 and sh-NC. All mice received subcutaneous lateral injection of $769-\mathrm{P}$ cells $\left(5 \times 10^{6}\right.$ cells). sh-SIRT6 or sh-NC were suspended in $200 \mu \mathrm{l}$ serum-free RPMI-1640 medium/Matrigel (1:1 mixture). All mice were housed and maintained under specific pathogen-free conditions in clear cages with free access to food and water, at room temperature $\left(22-25^{\circ} \mathrm{C}\right)$, with $50 \%$ humidity and 12 -h light/dark cycles. Tumor formation was monitored daily. All mice were anaesthetized with an intraperitoneal injection of $50 \mathrm{mg} / \mathrm{kg}$ pentobarbital sodium (Sigma-Aldrich; Merck KGaA) 2 weeks post-injection, and cervical vertebrae were dislocated. Following euthanasia, lack of heartbeat was used to verify mortality. The maximum diameter of the observed tumors was $14 \mathrm{~mm}$. No mice had multiple tumors. The tumors were removed and weighed, and whole tissue lysates were extracted from each tumor for western blot analysis.

Bioinformatics analysis. To determine the expression pattern and clinical characteristics of SIRT6, a public dataset [The Cancer Genome Atlas (TCGA)-KIRC cohort] was analyzed in the UALCAN database (http://ualcan.path.uab.edu). TCGA database (https://portal.gdc.cancer.gov) was used to download clinical data of patients with ccRCC and SIRT6 expression data. The association between SIRT6 expression level and survival in patients with ccRCC was assessed using GraphPad Prism v8 software (GraphPad Software, Inc.). The association between SIRT6 expression and survival in patients with pan-cancer was assessed using Kaplan-Meier plotter database (http://kmplot. com/analysis). The Kaplan-Meier plot was created in the following forms: i) All cases (based on the median SIRT6 expression value) and ii) Stage I and II/Stage III and IV (based on the best grouping with the smallest $\mathrm{P}$-value). $\mathrm{P}<0.05$ was considered to indicate a statistically significant difference (only statistical results are presented). The Human Protein Atlas database (https://www.proteinatlas.org) was used to compare SIRT6 protein expression in ccRCC tissues and normal tissues.

Statistical analysis. Statistical analysis was performed using SPSS 21.0 software (IBM Corp.). All experiments were performed in triplicate and data are presented as the mean \pm standard deviation. Survival analysis was performed using the Kaplan-Meier method and log-rank test. The $\chi^{2}$ test was used to assess the association between SIRT6 expression and the clinicopathological characteristics of patients with ccRCC. Paired Student's t-test was used to compare SIRT6 expression in tumor tissues (stage I/II or III/IV) and matched adjacent normal tissues. One-way ANOVA followed by Tukey's post hoc test were used to compare differences between multiple groups. $\mathrm{P}<0.05$ was considered to indicate a statistically significant difference.

\section{Results}

SIRT6 expression is associated with poor prognosis of patients with ccRCC. To determine the role of SIRT6 in ccRCC, mRNA-seq data within the UALCAN database was used to determine SIRT6 expression in ccRCC. The results demonstrated that SIRT6 expression was significantly higher in ccRCC tissues compared with normal tissues, and its high expression was dependent on cancer stage (Fig. 1A). In addition, ccRCC tissues at all stages highly expressed SIRT6 compared with normal tissues $(\mathrm{P}<0.001)$. To determine the association between SIRT6 expression and the prognosis of patients with ccRCC, Kaplan-Meier survival analysis was performed using the TCGA-KIRC dataset. A total of 342 cases were classified into two groups, based on the median SIRT6 expression value, with 171 cases in the high SIRT6 group and 171 cases in the low SIRT6 group. As presented in Fig. 1B, high SIRT6 expression was closely associated with poor prognosis of patients with ccRCC (log-rank, $\mathrm{P}=0.0009)$. In addition, the survival rates of patients with high SIRT6 expression were lower compared with those with low SIRT6 expression level, regardless of the disease stage $(\mathrm{P}=0.0595$ and $\mathrm{P}=0.0127$, respectively; Fig. 1C and D). The association between SIRT6 expression and the clinicopathological characteristics of patients in the dataset was assessed to determine the clinical significance of SIRT6 in ccRCC. The results demonstrated that SIRT6 expression was positively associated with TNM stage and distant metastasis $(\mathrm{P}<0.05$; Table II). The patient information used to perform Kaplan-Meier survival analysis is presented in Table SI. The Kaplan-Meier plotter database was used to determine the survival rates of patients with cancer in TCGA database. As presented in Fig. S1, SIRT6 expression was associated with poor prognosis of patients with ccRCC and hepatocellular carcinoma. Conversely, SIRT6 expression was associated with favorable prognosis in patients with bladder carcinoma, cervical squamous cell carcinoma, head and neck squamous cell carcinoma, pancreatic adenocarcinoma, stomach adenocarcinoma and uterine corpus endometrial carcinoma.

The Human Protein Atlas database was used to compare SIRT6 protein expression between ccRCC tissues and normal tissues. As presented in Fig. 1E, SIRT6 immunohistochemical staining was substantially stronger in ccRCC tissues compared with normal tissues. Western blot analysis was subsequently performed to verify these results, using tissue samples obtained from 20 patients with ccRCC. As presented in Fig. 1F, SIRT6 protein expression was significantly higher in ccRCC tissues compared with normal tissues. Quantitative densitometer analysis demonstrated that SIRT6 was highly expressed in $16 / 20$ pairs of ccRCC tissues $(\mathrm{P}<0.01$ or $\mathrm{P}<0.001$; Fig. 1G). In addition, RT-qPCR analysis was performed to detect SIRT6 expression in 40 pairs of ccRCC tissues and adjacent normal tissues. The results demonstrated that SIRT6 expression was upregulated 27-fold on average in the TNM (I-II) stages of ccRCC and 43-fold on average in the TNM (III-IV) stages $(\mathrm{P}<0.01$ or $\mathrm{P}<0.001$; Fig. $1 \mathrm{H})$. To assess the significance of SIRT6 expression in ccRCC, the association between SIRT6 expression and the clinicopathological characteristics were assessed using ccRCC tissues. The results demonstrated that high SIRT6 expression was significantly associated with higher tumor TNM stage and distant metastasis in ccRCC (Table III). However, no significant differences were observed between SIRT6 expression and age or sex. These results suggest that SIRT6 expression is upregulated, and significantly associated with TNM stage and distant metastasis in ccRCC. This is consistent with the results from TCGA database (Table II). Taken together, these results suggest that SIRT6 acts as a proto-oncogene in ccRCC. 
A

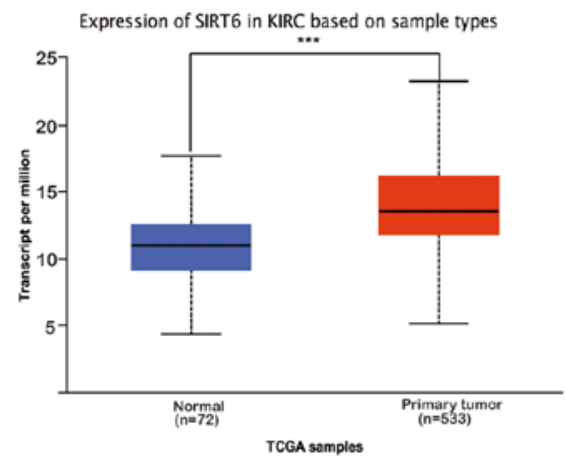

Expression of SIRT6 in KIRC based on individual cancer stages

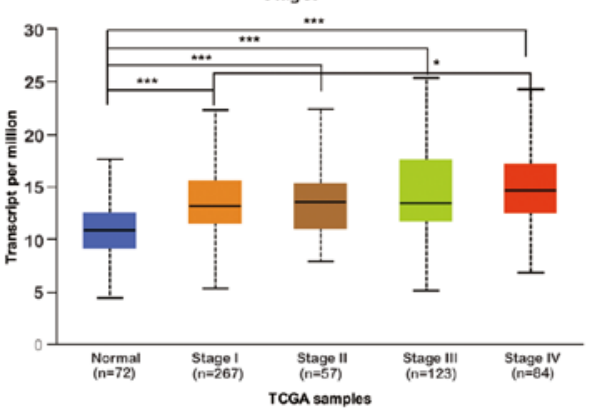

B

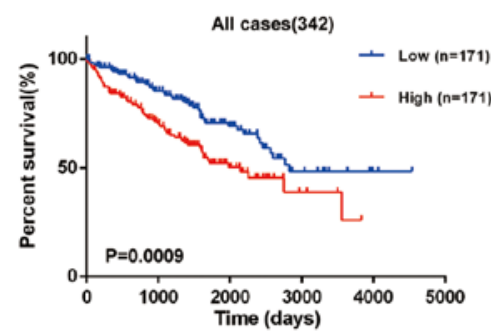

C

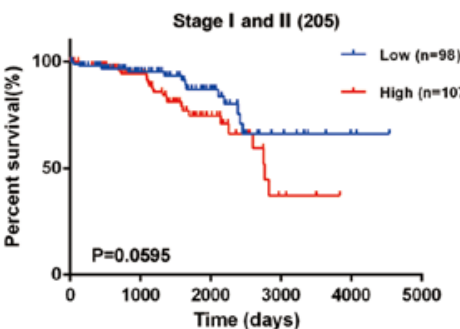

D

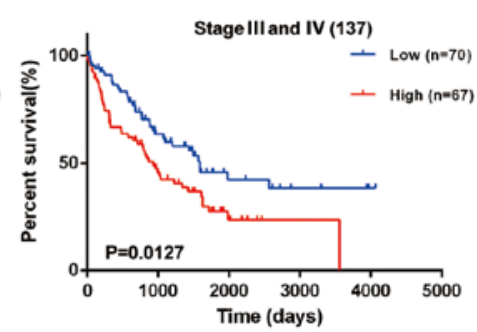

E

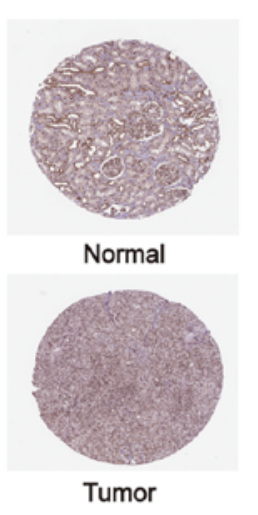

$\mathrm{F}$

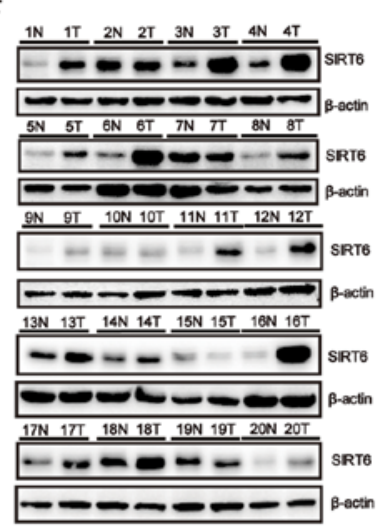

G

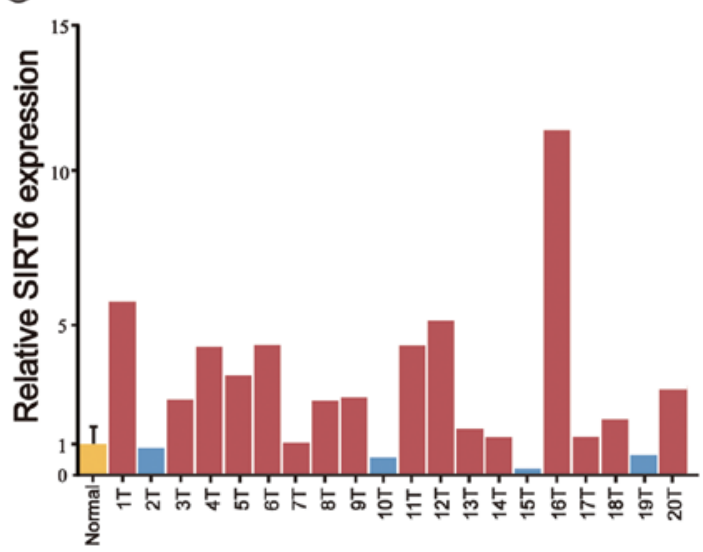

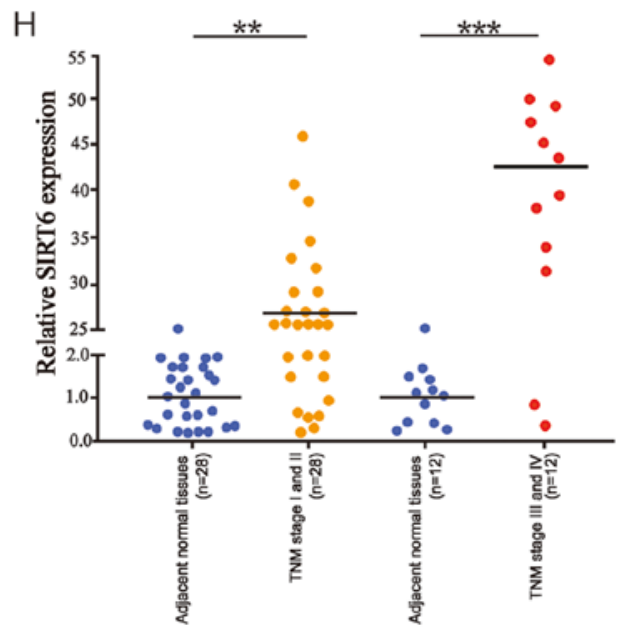

Figure 1. Upregulation of SIRT6 expression is associated with poor prognosis of ccRCC. (A) Differential expression of SIRT6 between ccRCC tissues and normal tissues. (B) Kaplan-Meier plot and log-rank test were used to assess overall survival time in patients with ccRCC, based on SIRT6 expression in TCGA databased and the clinical information of the patients with ccRCC. (C) Kaplan-Meier plot presenting the survival of the patients at stages I and II. (D) Kaplan-Meier plot presenting the survival of patients at stages III and IV. (E) Representative images of immunohistochemistry staining of SIRT6 in paired cancer tissues and adjacent normal tissues via the Human Protein Atlas. (F) Western blot analysis was performed to detect SIRT6 protein expression in ccRCC tissues and adjacent normal tissues. $\beta$-actin was used as the loading control. (G) Densitometric quantitative analysis of SIRT6 protein expression in 20 pairs of ccRCC tissues and adjacent normal tissues. (H) SIRT6 mRNA expression in 40 pairs of cancer tissues and adjacent normal tissues. Control refers to normal kidney tissues, and SIRT6 expression was normalized to the control. SIRT6 mRNA expression was calculated using the comparative Ct method. Relative expression intensity values were calculated using the $2^{-\Delta \Delta C q}$ method. " $\mathrm{P}<0.05,{ }^{* *} \mathrm{P}<0.01,{ }^{* * *} \mathrm{P}<0.001$. SIRT6, sirtuin 6; ccRCC, clear cell renal cell carcinoma; TCGA, The Cancer Genome Atlas; KIRC, Kidney Renal Clear Cell Carcinoma; N, normal; T, tumor; TNM, tumor-node-metastasis. 
Table II. Association between SIRT6 expression and the clinicopathological characteristics in patients with clear cell renal cell carcinoma $(n=342)$.

\begin{tabular}{|c|c|c|c|c|}
\hline \multirow[b]{2}{*}{ Characteristic } & \multicolumn{2}{|c|}{ SIRT6 expression (TCGA) } & \multirow[b]{2}{*}{$\begin{array}{l}\text { Total number } \\
\text { of patients, } n\end{array}$} & \multirow[b]{2}{*}{ P-value } \\
\hline & $<\operatorname{Median}(\mathrm{n}=171)$ & $\begin{array}{c}\geq \text { Median } \\
(\mathrm{n}=171)\end{array}$ & & \\
\hline Age, years & & & & 0.4479 \\
\hline$<60$ & 76 & 83 & 159 & \\
\hline$\geq 60$ & 95 & 88 & 183 & \\
\hline Sex & & & & 0.3069 \\
\hline Male & 116 & 107 & 223 & \\
\hline Female & 55 & 64 & 119 & \\
\hline TNM stage & & & & $0.0058^{\mathrm{a}}$ \\
\hline I-II & 115 & 90 & 205 & \\
\hline III-IV & 56 & 81 & 137 & \\
\hline Distant metastasis & & & & $0.0122^{\mathrm{b}}$ \\
\hline Negative & 144 & 125 & 269 & \\
\hline Positive & 27 & 46 & 73 & \\
\hline
\end{tabular}

${ }^{\mathrm{a}} \mathrm{P}<0.01 .{ }^{\mathrm{b}} \mathrm{P}<0.05$. SIRT6, sirtuin 6; TCGA, The Cancer Genome Atlas; TNM, tumor-node-metastasis.

Table III. Association between SIRT6 expression and the clinicopathological characteristics of patient with ccRCC ( $\mathrm{n}=40$ ).

\begin{tabular}{lcccc}
\hline & \multicolumn{2}{c}{ SIRT6 expression } & & \\
\cline { 2 - 3 } Characteristic & $<$ Median $(\mathrm{n}=20)$ & $\begin{array}{c}\text { Median } \\
(\mathrm{n}=20)\end{array}$ & $\begin{array}{c}\text { Total number } \\
\text { of patients, } \mathrm{n}\end{array}$ & P-value \\
\hline Age, years & & & & 0.5073 \\
$<60$ & 14 & 12 & 26 & 0.5186 \\
$\geq 60$ & 6 & 8 & 14 & $0.0058^{\mathrm{b}}$ \\
Sex & 13 & 11 & 24 & $0.0177^{\mathrm{a}}$ \\
Male & 7 & 9 & 16 & \\
Female & 18 & 10 & 28 & 12 \\
TNM stage & 2 & 10 & 32 & \\
I-II & & & 8 & \\
III-IV & 19 & 13 & 7 &
\end{tabular}

${ }^{\mathrm{a}} \mathrm{P}<0.05,{ }^{\mathrm{b}} \mathrm{P}<0.01$. SIRT6, sirtuin 6; ccRCC, clear cell renal cell carcinoma; TNM, tumor-node-metastasis.

SIRT6 knockdown inhibits ccRCC cell proliferation, migration and invasion. The effect of SIRT6 on cell proliferation, migration and invasion in ccRCC was assessed. ccRCC-derived 769-P and 786-O cells were transfected with si-NC or si-SIRT6. As expected, SIRT6 knockdown significantly decreased the proliferative rate $(\mathrm{P}<0.05$; Fig. $2 \mathrm{~A}$ and $\mathrm{P}<0.01$ or $\mathrm{P}<0.001$; Fig. $2 \mathrm{~B})$ and colony formation ability $(\mathrm{P}<0.05$ or $\mathrm{P}<0.01$; Fig. 2C) of 769-P and 786-O cells. Consistent with these results, the migration and the invasion assays demonstrated that SIRT6 knockdown attenuated the cell migratory and invasive abilities $(\mathrm{P}<0.05$ or $\mathrm{P}<0.01)$ (Fig. $2 \mathrm{D}$ and $\mathrm{E})$.
SIRT6 promotes ccRCC cell proliferation via Bcl-2. It has been demonstrated that SIRT6 prevents the mitochondrial translocation of Bax in liver cancer cells, and SIRT6-mediated deacetylation $\mathrm{Ku} 70$ attenuates apoptotic cell death of hepatocellular carcinoma (HCC) cells (17), suggesting that SIRT6 may participate in the pro-survival Bcl-2 pathway. To confirm this hypothesis, 769-P and 786-O cells were transfected with the si-NC or si-SIRT6 in the present study, and western blot analysis was performed to detect the protein expression levels of Bcl-2 and Bax. As presented in Fig. 3A, Bcl-2 expression notably decreased, while Bax expression notably increased 

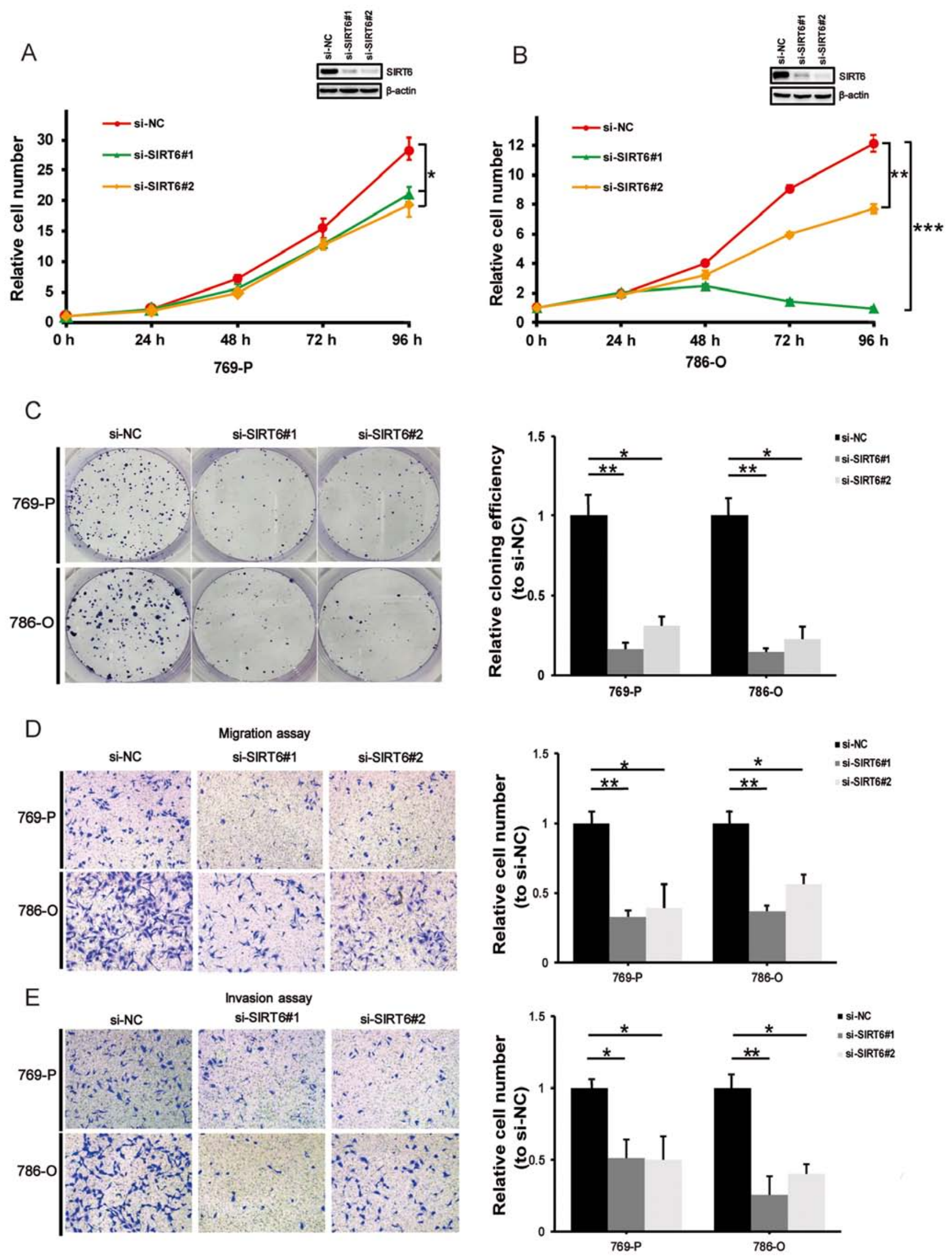

Figure 2. SIRT6 knockdown inhibits proliferation, migration and invasion of ccRCC cells. (A and B) The results of the Cell Couting Kit-8 assay. ccRCC-derived 769-P and 786-O cells were transfected with si-NC or si-SIRT6 (si-SIRT6\#1 and si-SIRT6\#2). Transfection efficiency was detected via western blot analysis (insets). $\beta$-actin was used as the loading control. (C) The results of the colony formation assay. ccRCC-derived 769-P and 786-O cells were transfected with si-NC or si-SIRT6 (si-SIRT6\#1 and si-SIRT6\#2). Cells were subjected to (D) migration (E) invasion assays $24 \mathrm{~h}$ post-transfection. The results were analyzed using ImageJ software and expressed in histograms. Data are presented as the mean \pm standard deviation $(\mathrm{n}=3) .{ }^{*} \mathrm{P}<0.05,{ }^{* * *} \mathrm{P}<0.01,{ }^{* * * *} \mathrm{P}<0.001$. SIRT6, sirtuin 6; ccRCC, clear cell renal cell carcinoma; si, small interfering; NC, negative control. 


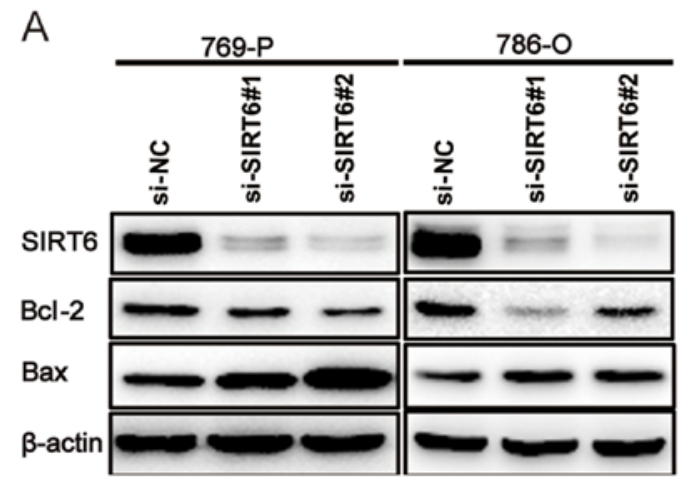

B

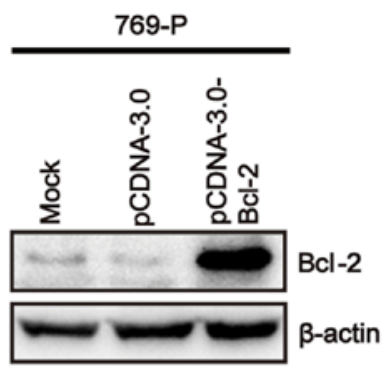

C

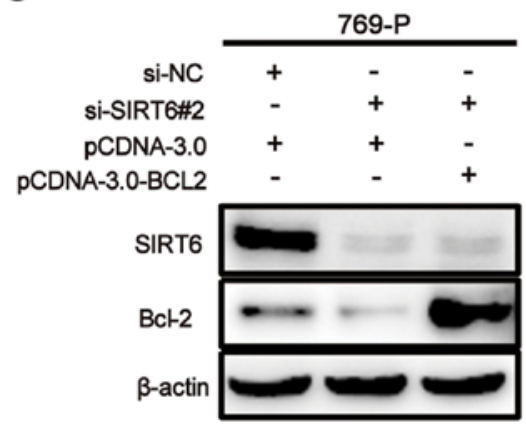

E

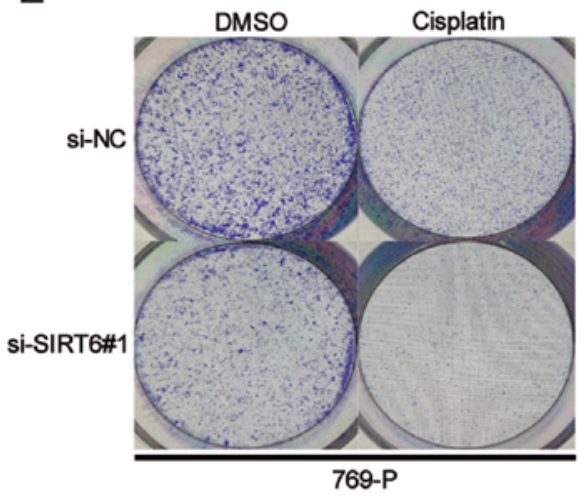

$\mathrm{F}$
D
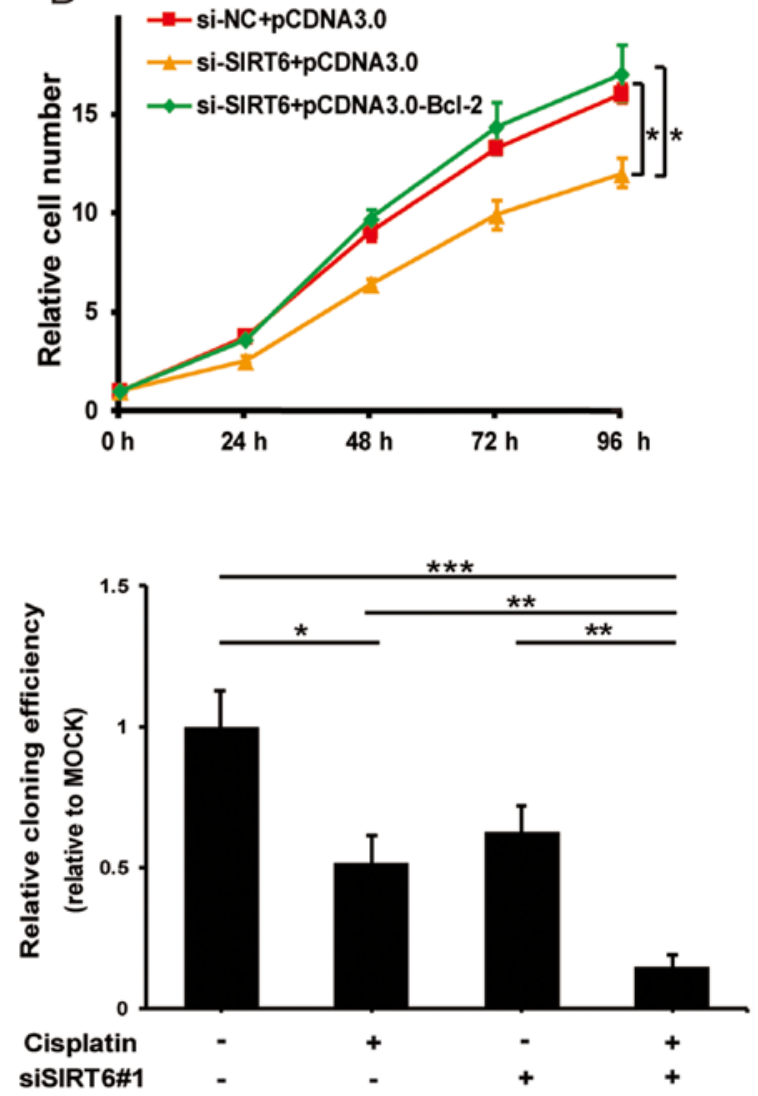

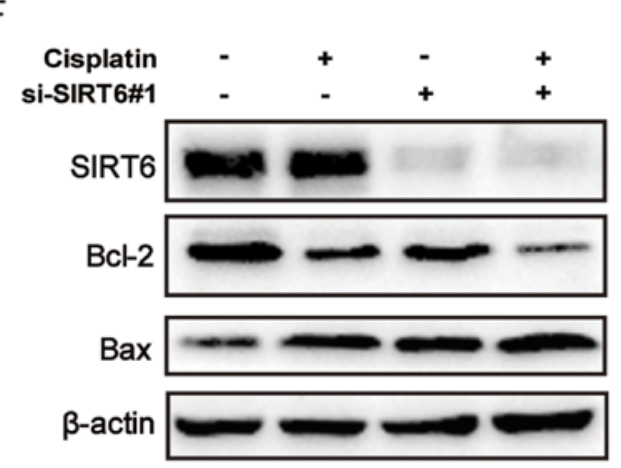

Figure 3. SIRT6 promotes the proliferation of clear cell renal cell carcinoma cells via regulation of Bcl-2. (A) 769-P and 786-O cells were transfected with si-NC or si-SIRT6 (si-SIRT6\#1 and si-SIRT6\#2) and western blot analysis was performed to detect Bcl- 2 and Bax protein expression levels. $\beta$-actin was used as the loading control. (B) 769-P cells were transfected with empty vector (pcDNA3.0) or pcDNA3.0-Bcl-2 overexpression vector and western blot analysis was performed to detect Bcl-2 protein expression. $\beta$-actin was used as the loading control. (C) 769-P cells were transfected with the indicated combinations of si-NC/si-SIRT6 plus pCDNA3.0/pCDNA3.0-Bcl-2 overexpression vectors and western blot analysis was performed to detect SIRT6 and Bcl-2 protein expression levels. $\beta$-actin was used as the loading control. (D) 769-P cells were transfected as in (B) and the Cell Counting Kit-8 assay was performed to assess cell proliferation. (E) 769-P cells were transfected with si-NC or si-SIRT6 (si-SIRT6\#1) and subsequently treated with DMSO or cisplatin (2.5 $\mu \mathrm{M})$. Cell colony formation was assessed after 2 weeks. (F) 769-P cells transfected with si-SIRT6\#1 were treated with or without cisplatin. Western blot analysis was performed after 2 weeks to detect Bcl-2 and Bax protein expression levels. ${ }^{*} \mathrm{P}<0.05,{ }^{* *} \mathrm{P}<0.01,{ }^{* * *} \mathrm{P}<0.001$. SIRT6, sirtuin 6; Bcl-2, B-cell lymphoma 2; si, small interfering; NC, negative control; DMSO, dimethyl sulfoxide. 
following SIRT6 knockdown in ccRCC cells. Bcl-2 expression was subsequently overexpressed in 769-P cells, and the transfection efficiency is presented in Fig. 3B. Bcl-2 expression was overexpressed following SIRT6 knockdown. Notably, the results demonstrated that SIRT6 depletion-mediated decrease in the proliferative ability of 769-P cells was restored following overexpression of $\mathrm{Bcl}-2(\mathrm{P}<0.05)$ (Fig. 3C and D). Taken together, these results suggest that SIRT6 promotes ccRCC cell proliferation, at least in part, through regulation of the pro-survival Bcl-2 pathway.

SIRT6 knockdown enhances cisplatin sensitivity of ccRCC cells. The results of the present study suggest that SIRT6 acts as a proto-oncogene in ccRCC. Thus, it was assessed whether SIRT6 affects the chemosensitivity of ccRCC cells via the colony formation assay. SIRT6-depleted 769-P cells were treated with or without $2.5 \mu \mathrm{M}$ cisplatin. After 2 weeks of treatment, viable cells colonies were stained with crystal violet and observed under a microscope. As presented in Fig. 3E $(\mathrm{P}<0.05$ or $\mathrm{P}<0.01$ or $\mathrm{P}<0.0001)$, the number of cell colonies in cisplatin-exposed SIRT6-knockdown cells were significantly smaller compared with the control cells treated with cisplatin. In addition, western blot analysis was performed to detect the related protein levels in these four groups. As presented in Fig. 3F, Bcl-2 protein expression significantly decreased in SIRT6 knockdown cells exposed to cisplatin, while Bax protein expression significantly increased. Collectively, these results suggest that SIRT6 knockdown enhances the sensitivity of ccRCC cells to cisplatin.

SIRT6 knockdown inhibits tumor proliferation in vivo. To determine the potential effect of SIRT6 knockdown on tumor growth in vivo, RT-qPCR and western blot analyses were performed to verify the efficiency of SIRT6 knockdown on stable 769-P cells $(\mathrm{P}<0.01)$ (Fig. 4A and B). A $\mathrm{BALB} / \mathrm{c}$ xenograft model was subsequently established via subcutaneous injection of SIRT6-depleted 769-P cells. The representative images of tumors in the control and experimental groups were taken 2 weeks after injection. The results demonstrated that the tumor weight was significantly lower in the sh-SIRT6 group compared with the sh-NC group $(\mathrm{P}<0.01)$ (Fig. 4C and D), suggesting that SIRT6 knockdown notably decreases the tumor growth rate arising from 769-P cells in vivo. The average body weight of both groups of mice was recorded over a 2 -week period and the changes in body weight were plotted (Fig. 4E). In the last 3 days of the experiment, a small number of mice lost weight; however, no statistically significant differences were observed between the two groups. Based on the conclusion that SIRT6 plays a role as an oncogene in ccRCC, If the tumor continued to grow in the mice for a week, the weight of mice may drop $>10 \%$ of the starting weight, and mice in the sh-NC group may experience more significant weight loss compared with that in mice in the sh-SIRT6 group. Western blot analysis demonstrated that the protein expression levels of Bcl-2 and Bax were downregulated and upregulated in SIRT6-depleted tumors compared with the control tumors, respectively (Fig. 4F). Taken together, these results suggest that SIRT6 prevents the tumor forming ability of ccRCC cells by suppressing the pro-survival Bcl-2 pathway.

\section{Discussion}

To the best of our knowledge, the present study was the first to demonstrate that SIRT6 participates in the acquisition and/or promotion of the malignant properties of ccRCC through potentiation of the pro-survival Bcl-2 pathway. Taken together, the results of the present study suggest that SIRT6 acts as a proto-oncogene in ccRCC, and may be a potential therapeutic target of ccRCC.

Increasing evidence suggests that SIRT6 acts as a tumor suppressor in lung, breast and pancreatic cancers $(11,12,21)$. Conversely, it has also been demonstrated that SIRT6 acts as a proto-oncogene in other types of cancer. For example, Ming et al (22) reported that UV exposure-mediated induction of SIRT6 stimulates cyclooxygenase 2 expression through inhibition of the adenylate-activated protein kinase pathway, thereby promoting the proliferation, as well as the survival, of the epidermal layer in skin. Notably, skin tumor formation was significantly attenuated in SIRT6-knockout mice. In addition, Bauer et al (23) demonstrated that SIRT6-induced cytokine secretion and cell motility is promoted by activation of calcium channels in pancreatic cancer cells. Khongkow et al (24) reported that SIRT6 is highly expressed in paclitaxel- and epirubicin-resistant MCF-7 breast cancer cells compared with their parental cells. According to their results, gene silencing and overexpression of SIRT6 increases and decreases the sensitivity to paclitaxel and epirubicin, respectively. In addition, although renal cell carcinoma is not sensitive to radiotherapy and chemotherapy, cisplatin is one of the most extensive and effective chemotherapeutic agents for several types of human cancer, including testicular, bladder, ovarian, colorectal, lung and head and neck cancers (25-27). Cisplatin acts by directly binding to DNA to produce a cisplatin-DNA adduct. If cisplatin-DNA adducts are not efficiently processed by the cellular repair mechanism, the programmed cell death pathway is initiated. Molecular mechanisms that disrupt these pre-apoptotic signals are thought to be responsible for tumor resistance to chemotherapy (28). Thus, cisplatin has been the standard experimental drug to study the molecular mechanism of chemosensitivity in renal cell carcinoma (29-31). In accordance with these observations, the results of the present study demonstrated that high SIRT6 expression was associated with poor prognosis of patients with ccRCC, and SIRT6 knockdown decreased the proliferative, migratory and invasive abilities of ccRCC cells, and enhanced their sensitivity to cisplatin. Furthermore, SIRT6 knockdown suppressed tumor growth in vivo, suggesting that SIRT6 acts as a proto-oncogene in ccRCC.

Notably, it has been demonstrated that SIRT6 prohibits cancer cell apoptosis (32-34). In prostate cancer cells, SIRT6 knockdown decreases the expression levels of pro-survival/anti-apoptotic Bcl-2, and enhances their chemosensitivity (15). In liver cancer cells, SIRT6 blocks the mitochondrial translocation of pro-apoptotic Bax, thereby decreases the apoptotic rate of HCC cells via deacetylation of Ku70 (17). Based on the results of the present study, SIRT6 knockdown in ccRCC cells downregulated and upregulated Bcl-2 and Bax expression, respectively, which enhanced their sensitivity to cisplatin. In addition, overexpression of $\mathrm{Bcl}-2$ in ccRCC cells restored SIRT6 depletion-mediated decrease of 

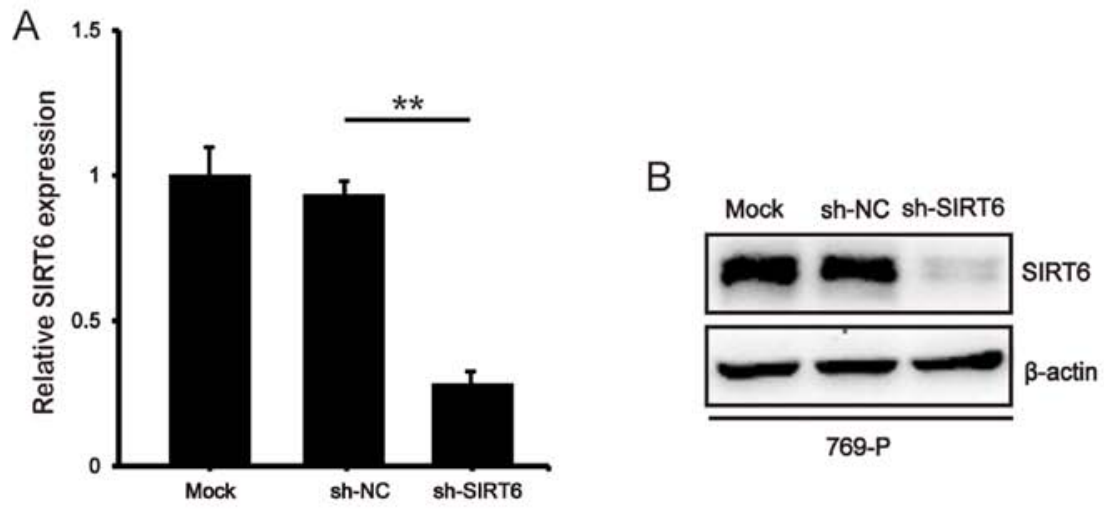

C

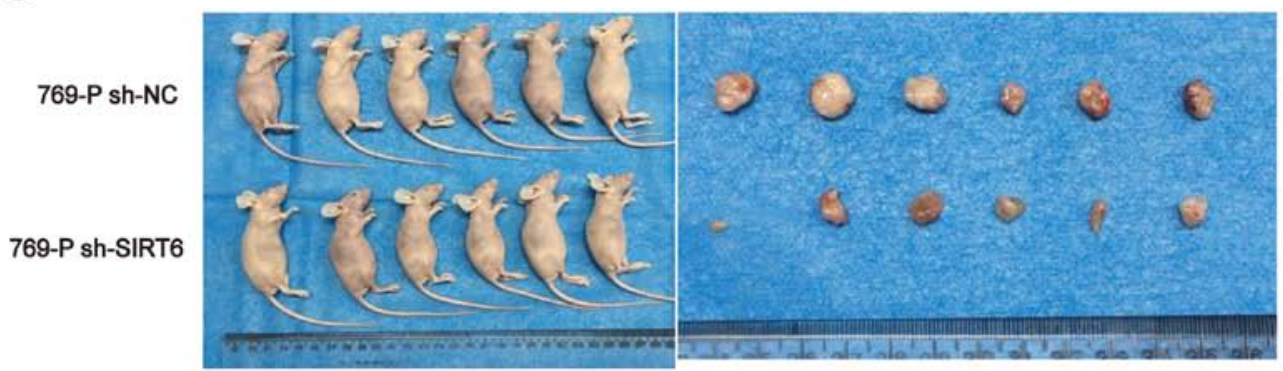

$\mathrm{D}$

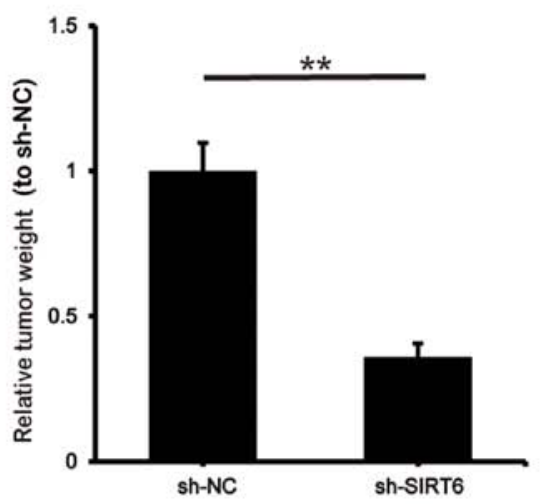

E

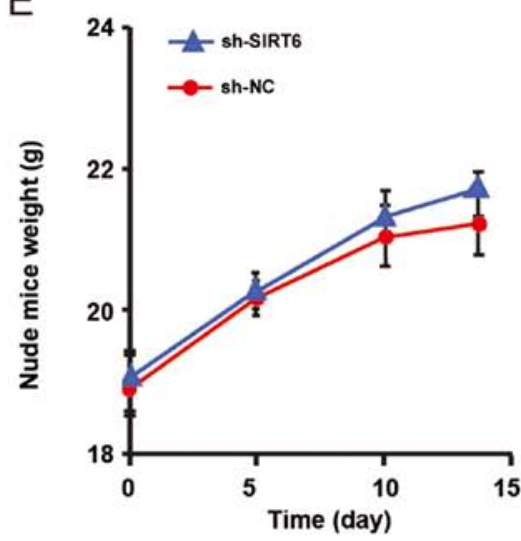

$\mathrm{F}$ sh-SIRT6

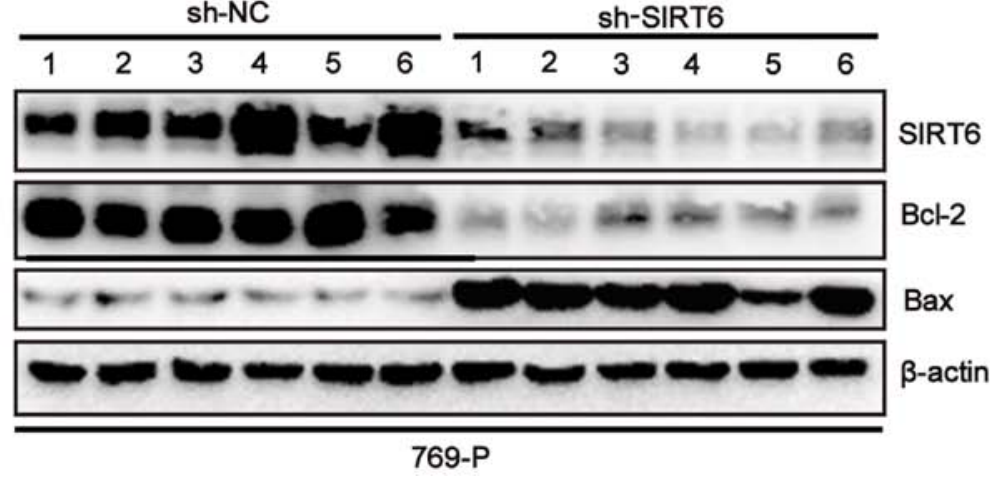

Figure 4. SIRT6 knockdown attenuates the proliferation of clear cell renal cell carcinoma cells in vivo. SIRT6 mRNA (A) and protein (B) expression levels were significantly downregulated following transfection of 769-P cells with sh-SIRT6 lentivirus. (C) Representative images of tumors in the control and experimental groups 2 weeks after transfecting 769-P cells with sh-NC or sh-SIRT6. (D) Quantitative analysis of the tumor weight. (E) Weight changes in mice over a 2-week period. (F) Western blot analysis was performed to detect SIRT6, Bcl-2 and Bax protein expression levels. $\beta$-actin was used as the loading control. ${ }^{* *} \mathrm{P}<0.01$. SIRT6, sirtuin 6; sh, short hairpin; NC, negative control; Bcl-2, B-cell lymphoma 2.

their proliferative rate. $\mathrm{Bcl}-2$ is one of the most representative anti-apoptotic gene products, whereby aberrant $\mathrm{Bcl}-2$ expression in cancer cells is associated with their histological types, poor prognosis of patients, and resistance to radiotherapy and chemotherapy (35-37). Elevated Bcl-2 expression dissociates Bax-Bax homo-dimers, and the resultant free Bax and $\mathrm{Bcl}-2$ form is 
more stable than Bax-Bcl-2 hetero-dimers, thereby preventing Bax-Bax homo-dimer-induced apoptotic cell death $(38,39)$. SIRT6-mediated differential regulation of Bcl-2 and Bax disrupts the balance between them, thereby suppressing mitochondrial apoptotic cell death (17).

The present study was not without limitations. For example, downstream pathway components of SIRT6 promoting cancer, including TRPM2 and TNF1 $\alpha$, and the in vivo verification of the effect of SIRT6 on cisplatin sensitivity were not investigated.

In conclusion, the results of the present study suggest that SIRT6 regulates Bcl-2 to acquire and/or promote the malignant properties of ccRCC, and thus may act as an attractive therapeutic target of ccRCC.

\section{Acknowledgements}

The authors would like to thank Dr Haotian Xing (Department of Urology, The First Hospital of China Medical University, Shenyang, China) for his guidance on the bioinformatics analysis.

\section{Funding}

The present study was supported in part by the National Natural Science Foundation of China (grant nos. 81672523 and 81472404).

\section{Availability of data and materials}

The datasets used and/or analyzed during the present study are available from the corresponding authors upon reasonable request.

\section{Authors' contributions}

YZ and MY designed and supervised the present study. JA, JY, $\mathrm{KL}$ and $\mathrm{ZZ}$ performed the in vitro experiments and collected the data, while JY and YY performed the in vivo experiments and collected the data. JA and JY analyzed and interpreted the results. JA, MY and YZ drafted the initial manuscript and made substantial revisions. A, JY and YZ confirm the authenticity of all the raw data. All authors have read and approved the final manuscript. J

\section{Ethics approval and consent to participate}

The present study was approved by the Ethics Committee of the First Hospital of China Medical University (Institutional review board no. 2018-64-2; Shenyang, China) and performed in accordance with the Declaration of Helsinki (19). Written informed consent was provided by all patients prior to the study start. All animal experiments were approved by The Ethics Committee of Medical Experimental Animal Welfare of China Medical University (approval no. 2019227; Shenyang, China).

\section{Patient consent for publication}

Not applicable.

\section{Competing interests}

The authors declare that they have no competing interests.

\section{References}

1. Hsieh JJ, Purdue MP, Signoretti S, Swanton C, Albiges L, Schmidinger M, Heng DY, Larkin J and Ficarra V: Renal cell carcinoma. Nat Rev Dis Primers 3: 17009, 2017.

2. Gray R, Hentschke R, Isaac S, Mead R, Ozturk A, Rieley P, Smale K and Stern R: Sampling variation of reported results. Nature 234: 230-231, 1971.

3. Chen YL, Ge GJ, Qi C, Wang H, Wang HL, Li LY, Li GH and Xia LQ: A five-gene signature may predict sunitinib sensitivity and serve as prognostic biomarkers for renal cell carcinoma. J Cell Physiol 233: 6649-6660, 2018.

4. Escudier B, Porta C, Schmidinger M, Rioux-Leclercq N, Bex A, Khoo V, Gruenvald V and Horwich A: Renal cell carcinoma: ESMO Clinical Practice Guidelines for diagnosis, treatment and follow-up. Ann Oncol 27: v58-v68, 2016.

5. Lam JS, Shvarts O, Leppert JT, Pantuck AJ, Figlin RA and Belldegrun AS: Postoperative surveillance protocol for patients with localized and locally advanced renal cell carcinoma based on a validated prognostic nomogram and risk group stratification system. J Urol 174: 466-472, 2005.

6. Wang Y, He J, Liao M, Hu M, Li W, Ouyang H, Wang X, Ye T, Zhang Y and Ouyang L: An overview of Sirtuins as potential therapeutic target: Structure, function and modulators. Eur J Med Chem 161: 48-77, 2019.

7. Haigis MC and Sinclair DA: Mammalian sirtuins: Biological insights and disease relevance. Ann Rev Pathol 5: 253-295, 2010.

8. Sebastián C, Zwaans BM, Silberman DM, Gymrek M, Goren A, Zhong L, Ram O, Truelove J, Guimaraes AR, Toiber D, et al: The histone deacetylase SIRT6 is a tumor suppressor that controls cancer metabolism. Cell 151: 1185-1199, 2012.

9. Marquardt JU, Fischer K, Baus K, Kashyap A, Ma S, Krupp M, Linke M, Teufel A, Zechner U, Strand D, et al: Sirtuin-6-dependent genetic and epigenetic alterations are associated with poor clinical outcome in hepatocellular carcinoma patients. Hepatology 58: 1054-1064, 2013.

10. Zhang $\mathrm{C}, \mathrm{Yu} \mathrm{Y}$, Huang Q and Tang K: SIRT6 regulates the proliferation and apoptosis of hepatocellular carcinoma via the ERK1/2 signaling pathway. Mol Med Rep 20: 1575-1582, 2019.

11. Han Z, Liu L, Liu Y and Li S: Sirtuin SIRT6 suppresses cell proliferation through inhibition of Twist 1 expression in non-small cell lung cancer. Int J Clin Exp Pathol 7: 4774-4781, 2014.

12. Khongkow M, Olmos Y, Gong C, Gomes AR, Monteiro LJ, YagüeE, Cavaco TB, Khongkow P, Man EP, Laohasinnarong S, et al: SIRT6 modulates paclitaxel and epirubicin resistance and survival in breast cancer. Carcinogenesis 34: 1476-1486, 2013.

13. Qi W, Fitchev PS, Cornwell ML, Greenberg J, Cabe M, Weber CR, Roy HK, Crawford SE and Savkovic SD: FOXO3 growth inhibition of colonic cells is dependent on intraepithelial lipid droplet density. J Biol Chem 288: 16274-16281, 2013.

14. Colas E, Perez C, Cabrera S, Pedrola N, Monge M, Castellvi J, Eyzaguirre F, Gregorio J, Ruiz A, Llaurado M, et al: Molecular markers of endometrial carcinoma detected in uterine aspirates. Int J Cancer 129: 2435-2444, 2011

15. Liu Y, Xie QR, Wang B, Shao J, Zhang T, Liu T, Huang G and Xia W: Inhibition of SIRT6 in prostate cancer reduces cell viability and increases sensitivity to chemotherapeutics. Protein Cell 4: 702-710, 2013.

16. Desantis V, Lamanuzzi A and Vacca A: The role of SIRT6 in tumors. Haematologica 103: 1-4, 2018.

17. Tao NN, Ren JH, Tang H, Ran LK, Zhou HZ, Liu B, Huang AL and Chen J: Deacetylation of Ku70 by SIRT6 attenuates Bax-mediated apoptosis in hepatocellular carcinoma. Biochem Biophys Res Commun 485: 713-719, 2017.

18. Amin MB, Edge S, Greene F, Byrd DR, Brookland RK, Washington MK, Gershenwald JE, Compton CC, Hess KR, Sullivan DC, et al: AJCC cancer staging manual. (8th edition). Springer International Publishing, 739-747, 2017.

19. World Medical Association: World medical association declaration of Helsinki: Ethical principles for medical research involving human subjects. JAMA 310: 2191-2194, 2013. 
20. Livak KJ and Schmittgen TD: Analysis of relative gene expression data using real-time quantitative PCR and the 2(-Delta Delta C(T)) method. Methods 25: 402-408, 2001.

21. Kugel S, Sebastián C, Fitamant J, Ross KN, Saha SK, Jain E, Gladden A, Arora KS, Kato Y, Rivera MN, et al: SIRT6 suppresses pancreatic cancer through control of Lin28b. Cell 165: 1401-1415, 2016.

22. Ming M, Han W, Zhao B, Sundaresan NR, Deng CX, Gupta MP and He YY: SIRT6 promotes COX-2 expression and acts as an oncogene in skin cancer. Cancer Res 74: 5925-5933, 2014.

23. Bauer I, Grozio A, Lasigliè D, Basile G, Sturla L, Magnone M, Sociali G, Soncini D, Caffa I,Poggi A, et al: The NAD+-dependent histone deacetylase SIRT6 promotes cytokine production and migration in pancreatic cancer cells by regulating $\mathrm{Ca}^{2+}$ responses. J Biol Chemistry 287: 40924-40937, 2012.

24. Khongkow P, Gomes AR, Gong C, Man EP, Tsang JW, Zhao F, Monteiro LJ, Coombes RC, Medema RH, Khoo US and Lam EW: Paclitaxel targets FOXM1 to regulate KIF20A in mitotic catastrophe and breast cancer paclitaxel resistance. Oncogene 35: 990-1002, 2016.

25. Prestayko AW, D'Aoust JC, Issell BF and Crooke ST: Cisplatin (cis-diamminedichloroplatinum II). Cancer Treat Rev 6: 17-39, 1979.

26. Lebwohl D and Canetta R: Clinical development of platinum complexes in cancer therapy: An historical perspective and an update. Eur J Cancer 34: 1522-1534, 1998.

27. Galanski M: Recent developments in the field of anticancer platinum complexes. Recent Pat Anticancer Drug Discov 1: 285-295, 2006

28. Siddik ZH: Cisplatin: Mode of cytotoxic action and molecular basis of resistance. Oncogene 22: 7265-7279, 2003.

29. Hueber PA, Waters P, Clark P, Clarke P, Eccles M and Goodyer P: PAX2 inactivation enhances cisplatin-induced apoptosis in renal carcinoma cells. Kidney Int 69: 1139-1145, 2006.

30. Liu W, Chen H, Wong N, Haynes W, Baker CM and Wang X: Pseudohypoxia induced by miR-126 deactivation promotes migration and therapeutic resistance in renal cell carcinoma. Cancer Lett 394: 65-75, 2017

31. Yan L, Ding B, Liu H, Zhang Y, Zeng J, Hu J, Yao W, Yu G, An R, Chen Z, et al: Inhibition of SMYD2 suppresses tumor progression by down-regulating microRNA-125b and attenuates multi-drug resistance in renal cell carcinoma. Theranostics 9: $8377-8391,2019$.
32. Bai L, Lin G, Sun L, Liu Y, Huang X, Cao C, Guo Y and Xie C: Upregulation of SIRT6 predicts poor prognosis and promotes metastasis of non-small cell lung cancer via the ERK1/2/MMP9 pathway. Oncotarget 7: 40377-40386, 2016

33. Azuma Y, Yokobori T, Mogi A, Altan B, Yajima T, Kosaka T, Onozato R, Yamaki E, Asao T, Nishiyama M and Kuwano H: SIRT6 expression is associated with poor prognosis and chemosensitivity in patients with non-small cell lung cancer. J Surg Oncol 112: 231-237, 2015.

34. Strub T, Ghiraldini FG, Carcamo S, Li M, Wroblewska A, Singh R, Goldberg MS, Hasson D, Wang Z, Gallagher SJ, et al: SIRT6 haploinsufficiency induces BRAF melanoma cell resistance to MAPK inhibitors via IGF signalling. Nat Commun 9: 3440, 2018.

35. Xu L, Lin $\mathrm{X}$, Zheng $\mathrm{Y}$ and Zhou $\mathrm{H}$ : Silencing of heat shock protein 27 increases the radiosensitivity of non-small cell lung carcinoma cells. Mol Med Rep 20: 613-621, 2019.

36. Chrysovergis A, Papanikolaou VS, Tsiambas E, Ragos V, Peschos D and Kyrodimos E: Digital Analysis of BCL2 expression in laryngeal squamous cell carcinoma. Anticancer Res 39: 1253-1257, 2019.

37. Li H, Wang H, Deng K, Han W, Hong B and Lin W: The ratio of $\mathrm{Bcl}-2 / \mathrm{Bim}$ as a predictor of cisplatin response provides a rational combination of ABT-263 with cisplatin or radiation in small cell lung cancer. Cancer Biomark 24: 51-59, 2019.

38. Zha H, Aimé-Sempé C, Sato T and Reed JC: Proapoptotic protein Bax heterodimerizes with Bcl-2 and homodimerizes with Bax via a novel domain (BH3) distinct from $\mathrm{BH} 1$ and $\mathrm{BH} 2$. J Biol Chemistry 271: 7440-7444, 1996.

39. Reed JC, Zha H, Aime-Sempe C, Takayama S and Wang HG: Structure-function analysis of Bcl-2 family proteins. Regulators of programmed cell death. Adv Exp Med Biol 406: 99-112, 1996. International (CC BY-NC-ND 4.0) License. 